\title{
Bioethics and Literature: An Exciting Overlap
}

\author{
Grant Gillett • Lynne Bowyer
}

(C) Springer Science+Business Media Dordrecht 2014

This symposium represents the first major foray of the Journal of Bioethical Inquiry into what may well become one of its significant strands of scholarship. The $J B I$ has always encouraged critical and marginal areas of bioethics scholarship and particularly those which make use of contemporary continental philosophy and cultural theory in addition to traditional analytic methods. For that reason this symposium is an expression of a "natural fit" or a "match made in heaven" (or at least the Platonic version of that idea). The authors span times and sites in history and culture, from ancient Greece to present day Brisbane. They draw on a variety of literary genres and figures, ranging from Greek tragedy to an epic Chinese novel; from Jane Austen to William Styron, a major American novelist and essayist; from the modern English science fiction of Kazuo Ishiguro, a Japanese expatriate in London, to the 20th-century English poetry of Philip Larkin. The symposium also engages with some recurrent concerns in bioethics: transplantation and self-sacrifice; spirituality and mental disorder; death and dying; autonomy and being-in-the-world; alienation and the illness journey; and the margins of illness as health and culture intersect. There is a certain thematic unity as one might expect where the poetic and literary treatment of human phenomena comes into engagement with scientific biomedicine and its understandings of the vulnerabilities and failings that flesh is heir to. Holistic and narrative views of human life and the complex

G. Gillett $(\bowtie) \cdot$ L. Bowyer

Otago Bioethics Centre, University of Otago Medical School,

71 Frederick Street, DunedinPO Box 9011, New Zealand

e-mail: grant.gillett@otago.ac.nz

L. Bowyer

e-mail: lynne.bowyer@otago.ac.nz intersecting relationships and entanglements that form the human soul are bound to underscore many features of a patient's illness. However, these can be neglected in the relentless search for effective treatments and ever more sophisticated ways to understand the pathophysiology and genesis of disease. In the process of trying to master a hugely complex subject with an expanding range of expert technologized discourses, medical students can rapidly lose sight of the values and broadly humanistic and spiritual leanings that inspired them to take up medicine in the first place. That process of loss and "moral drift" often continues in residency and professional life and is only recognised when some personal or clinical crisis foregrounds it.

The process of socialisation and subjugation initiated by medical education can be withering in its intensity as students pursue accreditation and acceptance in their chosen vocation, which often requires sometimes punishing vocational and specialist training. In such an environment the echoes of an idealistic youth and the values that sustain us can become increasingly attenuated and faint. Bioethics and the literature spawned by illness help us to reclaim those fragments of self that have been starved of nourishment and desiccated through frantic neglect. This symposium aims to foster an interest in this re-humanising process on behalf of bioethics. It has been a great privilege to edit this collection and we hope you will enjoy the foray into literary appreciation and the poetic contemplation of illness and disease that it encourages.

Ancient Greece offers us Euripides' Alcestis, which is discussed by Robin Hankey and Grant Gillett (2014) as a contribution to an understanding of the currents running through discussions about close and costly gifts in live organ donation scenarios, especially those 
within families. Mal Parker from Brisbane (2014) gives us a series of poetic reflections on contemporary clinical life and reminds us of the ever present issues of mortality, compassion, and identity that we encounter there. Flora Huang and Grant Gillett (2014) engage with The Story of the Stone, whose title alludes to the overarching spiritual reality in which we live and move and have our being. This text is also known as The Dream of the Red Chamber, an allusion to the "red dust world" of human mortality and evanescent suffering. It confronts us with an understanding of the unique value and destiny of each human life as it is worked out in detail in our situated, complex, and passionate engagements with others. At the same time it resonates with the strivings of mystics and prophets as they are found in every culture. Jim Nelson (2014) brings Jane Austen into close conversation with a contemporary study of hypochondria to provide a rich exploration of the sociohistorically located faces of health and disease as they affect real human beings and all the ills that human flesh (and mind) succumbs to. William Styron, sensitively examined by Simon Walker (2014), is a major American novelist and essayist, who is brought to a remembrance of "all the joys" that had marked his life among others and which it would be wrong for him to negate by the self-destructive act of suicide. The struggle that ensues is a telling reflection on the value of human life and the importance of the engagement with others that fills life with meaning. Neil Pickering (2014) focuses on Philip Larkin and, in particular, Larkin's use of illness to examine human identity and the value of human life. Larkin's medical world is alienating and reductive: It extracts a person from the life context in which their richness of being is to be found, creating a rupture through which their humanity is drained away. Through a via negativa we are again invited to contemplate the uniqueness of each human being and the fact that life is beautiful. Kazuo Ishiguro's novel, Never Let Me Go, is submitted to an Heideggerian exploration by Lynne Bowyer (2014). What emerges is a nuanced re-conceptualisation of autonomy as an attentive and caring being-in-the-worldamong-others, based on a recognition of the fragility of life. It is a re-conceptualisation that is both more demanding and more content-ful than the commonly accepted rational individualist model that dominates much of contemporary bioethics. In so far as that model loses sight of our vulnerable and interdependent human existence, literature can be a kind of (philosophical) therapy for that lesion in our thought.

\section{References}

Bowyer, L. 2014. Autonomy and why you can "Never Let Me Go." Journal of Bioethical Inquiry 11(2). doi:10.1007/ s11673-014-9533-4.

Gillett, G., and R. Hankey. 2014. Duties to kin, through a tragicomic lens. Journal of Bioethical Inquiry 11(2). doi:10.1007/ s11673-014-9513-8.

Huang, F., and G. Gillett. 2014. Bao-yu: A mental disorder or a cultural icon? Journal of Bioethical Inquiry 11(2). doi: 10.1007/s11673-014-9511-x.

Nelson, J.L. 2014. Odd complaints and doubtful conditions: Norms of hypochondria in Jane Austen and Catherine Belling. Journal of Bioethical Inquiry 11(2). doi:10.1007/ s11673-014-9522-7.

Parker, M. 2014. Five pieces. Journal of Bioethical Inquiry 11(2). dois:10.1007/s11673-014-9523-6, 10.1007/s11673-0149529-0, 10.1007/s11673-014-9531-6, 10.1007/s11673-0149530-7 and 10.1007/s11673-014-9532-5.

Pickering, N. 2014. A random blend: The self in Philip Larkin's poems "Ambulances" and "The Building." Journal of Bioethical Inquiry 11(2). doi:10.1007/s11673-014-9521-8.

Walker, S. 2014. Spinoza, Styron, and the ethics of healing. Journal of Bioethical Inquiry 11(2). doi:10.1007/s11673014-9526-3. 